\title{
Gestasyonel diyabetin klinik periodontal durum ve plazma NT-ProBNP düzeylerinin değerlendirilmesi
}

Pınar Gümüş ${ }^{1}$, Özgün Özçaka ${ }^{1}$, Banu Öztürk Ceyhan², Aliye Akcalı ${ }^{1}$, Nazlı Gülriz Çeriं ${ }^{3}$, Çiğdem Yenisey ${ }^{4}$, Nurcan Buduneli ${ }^{1}$

\section{Selcuk Dental Journal, 2014; 2: 36-42}

\section{Evaluation of clinical periodontal status of gestational diabetes mellitus and NT-ProBNP levels}

Background: Few studies have investigated possible relationship between gestational diabetes mellitus (GDM) inflammatory periodontal diseases. The aim of this study was comparatively investigate clinical periodontal status and plasma NT-ProBNP levels in pregnant women with or without GDM.

Methods: Forty-three pregnant women with diagnosis of GDM and 41 women without GDM were included in the present study. Venous blood samples were obtained for determination of plasma NT-ProBNP levels. Clinical periodontal status was evaluated by probing depth $(\mathrm{mm})$, plaque and bleeding indices (\%) in 4 sites of all teeth present. Presence of polycystic ovary syndrome, history of abortus insulin resistance, sociodemographic parameters, and delivery week, birth weight was recorded. Data were analysed statistically by Mann-Whitney $U$ test and Pearson chi-square test.

Results: In the GDM group, age, fasting glucose, fasting insulin, HOMA-IR, hour 1,2 and 3 glucose levels were higher than those in the non-GDM group $(p<0,05)$. Clinical periodontal findings and plasma NT-ProBNP levels were similar in the study groups.

Conclusion: The present findings do not indicate a significant relationship between GDM and inflammatory periodontal disease. However, larger scale studies evaluating various biochemical parameters may provide further insight to this subject.

\section{KEY WORDS}

Gestational diabetes, inflammation, periodontal diseases, plasma
Başvuru Tarihi: 29 Kasım 2013 Yayına Kabul Tarihi: 18 Nisan 2014
Gestasyonel diabetes mellitus (GDM) ilk kez gebelikte ortaya çıkan ya da gebelik sırasında tanı konulan glukoz tolerans bozukluğudur (Turok ve ark 2003). Büyüme hormonu ve kortizol düzeylerindeki artış, insan plasental laktojen hormonunun varlığı, plasentadan insülinaz salımı ve artmış östrojen ve progesteron düzeyleri nedeniyle gebelik döneminde insülin direnci görülme intimali artar. Annenin artmış adipoz depoları, hareketin kısıtlanması ve kalori alımının artması glukoz intoleransı oluşmasında rol oynar (Karakurt ve ark 2009). GDM için tanı ve tarama testleri gebeliğin 24-28. haftaları arasında yapılmaktadır (Karakurt ve ark 2009). GDM'si olan annelerin bebeklerinde makrozomi, neonatal dönemde hipoglisemi, hipokalsemi, hiperbilirubinemi ve polisitemi tespit edilmiştir (Karakurt ve ark 2009, Ogata 1995).

Uzun süreli hiperglisemiye bağlı diyabet hastası bireylerde enflamatuvar periodontal hastalık şiddetinin arttığı gösterilirken periodontal hastalıkların diyabetin 6. komplikasyonu olduğu da ileri sürülmektedir (Löe 1993, Matthews 2002).

Periodontal hastalıkların mekanizması çok faktörlü ve oldukça karmaşıktır. Mikrobiyal dental plak patojenleri ve ürünleri enflamatuvar süreci bașlatmakta ve ilerlemesinde etkili olmaktadır. Çeşitli

\footnotetext{
${ }^{1}$ Ege Üniversitesi Diş Hekimliği Fakültesi Periodontoloji Anabilim Dalı Bornova, İzmir, Türkiye

2 Aydın Devlet Hastanesi Endokrinoloji Bölümü, Aydın, Türkiye

3 Adnan Menderes Üniversitesi Tıp Fakültesi Anatomi Anabilim Dalı, Aydın, Türkiye

${ }^{4}$ Adnan Menderes Üniversitesi Tıp Fakültesi Tıbbi Biyokimya Anabilim Dalı, Aydın, Türkiye
} 
araştırmalarda periodontal hastalıklar ile kardiyovasküler hastalıklar, diyabet, solunum yolu enfeksiyonları ve gebelik komplikasyonları arasındaki olası ilişkiler değerlendirilmiştir (Otomo-Cargel ve ark 2012). Kaynaklarda GDM ve periodontal hastalık arasındaki ilişkiyi destekleyen çalışmaların (Xiong ve ark 2006, Chokwiriyachit ve ark 2013, Xiong ve ark 2009) yanı sıra herhangi bir ilişki olmayan çalışmalarda (Dasanayake ve ark 2008, Xie ve ark 2013) bulunmaktadır.

NT-ProBNP'nin (Amino-Terminal pro-B-type natriuretic peptide) özellikle kardiyak hastalıklarda preklinik dönemde tespit edilerek kalp yetmezliğini geciktiren veya önleyen tedavilere olanak sağlayan bir belirteç olduğu ileri sürülmektedir (Lemos ve ark 2008). NTProBNP'nin diyabet hastalarında diyabet olmayan kontrol grubuna göre yüksek olduğu gösterilmiştir (Hildebrandt and Richards 2008, Feinkohl ve ark 2012). Diyabet hastalarındaki bu artışın özellikle kardiyovasküler komplikasyonlara bağlı olabileceği düşünülmektedir (Hildebrandt and Richards 2008). Yapılan literatür araştırmasında, NT-ProBNP'nin GDM ile ilişkisini araştıran sadece bir çalışmaya rastlanmış ve bu çalışmada, GDM'si olan gebeler ile kontrol grubuna dahil olan bireylerin plazma NT-ProBNP düzeyleri değerlendirilmiştir (Andreas ve ark 2011).

$\mathrm{Bu}$ bulgular ışığında, GDM'si olan gebelerde enflamatuvar periodontal hastalık şiddetinin artma eğiliminde olacağı hipotezinden yola çıkarak, GDM'si olan ve olmayan gebelerde klinik periodontal veriler ile plazma NT-ProBNP düzeylerinin karşılaştırmalı olarak incelenmesi amaçlanmıştır.

\section{GEREC ve YÖNTEM}

Çalışmamıza, Ekim 2012 - Mart 2013 tarihleri arasında Aydın Devlet Hastanesi Endokrinoloji bölümüne başvuran gebeler arasından dahil olma kriterlerini sağlayan toplam 84 gebe dahil edildi. Çalışmaya dahil edilme kriterleri; bilinen sistemik hastalığın bulunmaması, en az 20 dişin var olması ve ağızda sabit protez bulunmaması idi. Düzenli doktor kontrolünde olmayan ve GDM dışında gebeliğe bağlı başka bir sağlık sorunu bulunan gebeler çalışmaya dahil edilmedi.

Çalışma başlangıcında Ege Üniversitesi, Tıp Fakültesi Klinik Araştırmalar Etik Kurulu tarafından onay alındı (No:13-2/9). Tüm bireylere çalışma hakkında bilgi verildikten sonra herhangi bir işlem yapılmadan önce gönüllü olur formları imzalatıldı.

GDM tanısında ADA (Amerikan Diyabet Derneği) 2013 kılavuzunda önerilen 75 gramlık 2 saatlik Oral Glukoz Tolerans Testi (OGTT) kullanıldı. Açlık, 1. ve 2. saat tokluk kan şekeri ölçümleri yapıldı. Ayrıca, açılı ve tokluk insülin düzeyleri de ölçüldü, HOMA-IR değerleri belirlendi.

\section{Kan Örneklerinin Alınması}

Çalışmaya dahil edilen bireylerden klinik periodontal muayene öncesinde antekubital venden standart yöntem ile $5 \mathrm{ml}$. venöz kan örneği alındı. Kan örneklerinin $1500 \mathrm{~g}$ 'de 10 dakika santrifüj edilmesi ile ayrılan serum örnekleri laboratuvar analizlerinin yapılmasına kadar $-40^{\circ} \mathrm{C}$ 'de saklandı.

\section{Klinik Periodontal Ölçümler}

Sondalama derinliği $(\mathrm{mm})$ ile plak ve kanama indeksleri (var/yok şeklinde) dişlerin 4 bölgesinde ölçüldü. Ölçümler Williams periodontal sondası (HuFriedy, Chicago, IL, ABD) ile yapıldı ve en yakın milimetreye yuvarlandı. Tüm ölçümler önceden kalibre olan üç araştırmacı tarafından gerçekleştirildi (ÖÖ, PG, AA). Çalışmada tarafsızlı̆ın korunabilmesi için, körleme yapılarak ölçümleri yapan araştırıcıların ölçümleri yapılan gebelerin GDM durumu hakkında bilgi sahibi olmaması sağlandı.

\section{Plazma NT-ProBNP Analizi}

Plazma NT-proBNP konsantrasyonları ECLIA (Electrochemiluminescence immunassay) yöntemiyle Elecsys 2010 analizatörü (Roche Diagnostics, Mannheim, Almanya) ile ölçüldü. Ölçme aralığı üretici tarafından bildirilen $5-35.000 \mathrm{pg} / \mathrm{ml}$ olarak belirlendi.

Örneklerin laboratuvar analizlerini gerçekleştiren araştırıcının da körlenmesi için GDM'si olan ve olmayan gruplar özel kodlarla ayrılmadı. Ayrıca, gruplar ardışık değil karışık olarak kodlandı.

\section{İstatistiksel Analizler}

Elde edilen verilerin normal dağılım gösterip göstermediği Kolmogorov-Smirnov ve Shapiro-Wilk testleri ile değerlendirildi. Varyansların eşitliği için Levene's testi kullanilırken grupların karşılaştırılmasında Mann-Whitney $\mathrm{U}$ ve Pearson Kikare testleri kullanıldı. İstatistiksel değerlendirmeler için SPSS 17.0 (SPSS for Windows, SPSS Inc., Chicago, IL, ABD) paket programından yararlanıldı.

\section{BULGULAR}

Çalışmamıza, GDM'si olan 43, GDM'si olmayan 41 kadın olmak üzere toplam 84 gebe dahil edildi. Çalışma gruplarına ait biyokimyasal ve klinik periodontal veriler Tablo 1 'de verilmiştir. GDM'si olan grupta yaş $(p=0,001)$, vücut kütle indeksi (VKi) $(p<0,0001)$, açlık glukoz $(p=0,015)$, açlık insülin $(p<0,0001)$, HOMAIR $(p<0,0001), 1 . \quad(p<0,0001), 2$. $(p<0,0001)$ ve 3. saat $(p<0,0001)$ glukoz değerleri GDM'si olmayan gruptan anlamlı olarak daha yüksek bulundu. Klinik periodontal veriler karşılaştırıldığında ise; plak $(p=0,540)$, kanama $(p=0,426)$ ve sondalama derinliği $(p=0,518)$ değerlerinin her iki grupta benzer olduğu görüldü. 
Tablo 1.

\section{Çalıșma gruplarında periodontal durum ve GDM ile ilişkili bulgular}

\begin{tabular}{|lcc|}
\hline & GDM $(\mathrm{n}=43)$ & $\begin{array}{c}\text { GDM olmayan } \\
(\mathrm{n}=41)\end{array}$ \\
\hline Yaş (yıl) & $32,53(4,14)^{*}$ & $29,34(4,24)$ \\
\hline VKi & $27,80(3,91)^{\star}$ & $21,37(3,22)$ \\
\hline Açlık glukoz (mg/dl) & $88,3(13,2)^{\star}$ & $82,14(7,8)$ \\
\hline 1. saat (mg/dl) & $202,18(17,4)^{*}$ & $162,0(14,1)$ \\
\hline 2. saat (mg/dl) & $177,74(19,26)^{*}$ & $131,51(17,2)$ \\
\hline 3. saat (mg/dl) & $122,97(36,63)^{*}$ & $89,02(15,79)$ \\
\hline Açlık insülin (mu/ml) & $14,1(3,47)^{\star}$ & $11,53(2,02)$ \\
\hline HOMA-IR & $3,13(1,07)^{*}$ & $2,31(0,45)$ \\
\hline Plak (\%) & $54,88(29,38)$ & $50,49(27,04)$ \\
\hline Kanama (\%) & $55,12(29,46)$ & $48,54(25,45)$ \\
\hline Cep derinliği (mm) & $2,12(0,95)$ & $1,9(0,73)$ \\
\hline
\end{tabular}

Veriler ortalama (standart sapma) olarak verilmiştir.

VKi: Vücut kitle indeksi

* İstatistiksel olarak anlamlı fark $(p<0,05)$

Plazma NT-ProBNP değerleri çalışma gruplarında benzer bulundu $(p=0,250)$ (Grafik 1).

\section{Grafik 1.}

\section{Çalışma gruplarında plazma NT-ProBNP düzeyleri}

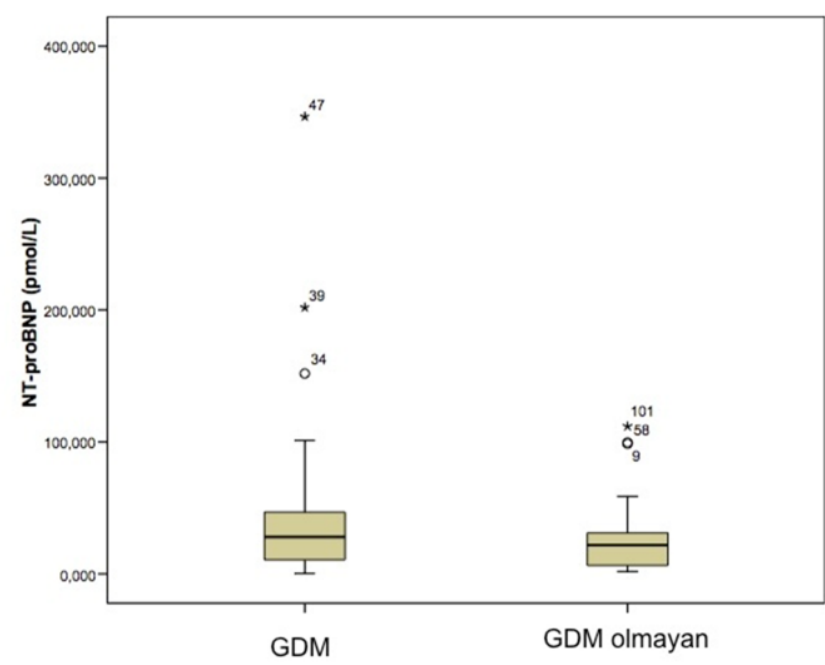

Tablo 2'de gebelere ait sosyo-demografik bulgular verilmiştir. GDM'si olan grupta düşük yapma oranı $(p=0,012)$, polikistik over sendromu (PCOS) hikayesi $(p=0,012)$ ve insülin direnci $(p<0,0001)$ GDM'si olmayan gruptan yüksek bulundu.
Tablo 2.

Çalışma gruplarında GDM ile ilişkili bulgular

\begin{tabular}{|lcc|}
\hline & GDM $(\mathrm{n}=43)$ & $\begin{array}{c}\text { GDM olmayan } \\
(\mathrm{n}=41)\end{array}$ \\
\hline Ailede DM hikayesi (var/yok) & $21 / 22$ & $13 / 28$ \\
\hline Düşük hikayesi (var/yok) & $7 / 36^{*}$ & $0 / 41$ \\
\hline Bebek doğum ağırlığı (gram) & $3386,13(480,42)$ & $3222,0(263,12)$ \\
\hline Makrozomi (var/yok) & 14001 & $0 / 41$ \\
\hline IGT hikayesi (var/yok) & 15342 & $0 / 41$ \\
\hline PCOS hikayesi (var/yok) & $7 / 36^{*}$ & $0 / 41$ \\
\hline İnsülin direnci (var/yok) & $28 / 15^{*}$ & 13271 \\
\hline Sigara & $36 / 3 / 4$ & 37558 \\
\hline (hiç içmemiş/içen/bırakmış) & & \\
\hline
\end{tabular}

Veriler ortalama (standart sapma) olarak verilmiştir.

DM: Diabetes mellitus; IGT: Bozulmuş Glikoz Toleransı

PCOS: Polikistik over sendromu

* İstatistiksel olarak anlamlı fark $(p<0,05)$

\section{TARTISSMA}

Gestasyonel diabetes mellitus (GDM) ilk kez gebelikte ortaya çıkan ya da gebelik sırasında tanı konulan glukoz tolerans bozuklugudur (Turok ve ark 2003). Uzun süreli hiperglisemiye maruz kalan diyabet hastalarında periodontal hastalık şiddetinin arttığı bilinmekte ve periodontal hastalıklar diyabetin 6. komplikasyonu olarak ileri sürülmektedir (Löe 1993, Matthews 2002). Periodontal hastalık ile GDM arasında da benzer bir ilişki olabileceği düşünülmüştür. Çalışmamızda, GDM olup olmamasına göre iki gruba ayrılan 84 gebe değerlendirilmiştir. Bulgularımız, GDM varlığının klinik periodontal durumu veya plazma NT-ProBNP değerini etkilemediği yönündedir.

Gebelik ile periodontal hastalık arasında çift yönlü bir ilişki olduğu düşünülmektedir. Yapılan bir deneysel gingivitis çalışmasında (Raber-Durlacher ve ark 1994), gebelik dönemi ile doğum sonrası 6. ay plak skorları arasında fark olmamasına rağmen dişetindeki enflamasyon şiddeti gebelikte daha fazla bulunmuştur. İki ayrı meta-analizin bulguları ise periodontal hastalığın ve gebelikte fetüs için risk oluşturduğu yönündeki görüşü destekler yöndedir (Khader ve Taani 2005, Corbella ve ark 2012). Gebelik komplikasyonları ile periodontal hastalıklar arasında ilişki olduğunu ileri süren çalışmaların aksine bu ilişkiyi gösteremeyen çalışmalar da bulunmaktadır. (Buduneli ve ark 2005, Ovadia ve ark 2007). Kumar ve arkadaşları (Kumar ve ark 2013) 
periodontitis ve gebelik komlikasyonları arasında ilişki olduğunu fakat gingivitis ile benzer bir ilişkinin olmadığını belirtmişlerdir. Aynı çalışmada hamilelik periodontitisinin preeklemsi, erken doğum ve düşük doğum ağırlıklı bebek gibi komlikasyonlarında riskini artırdığını da bildirmişlerdir (Kumar ve ark 2013). Benzer şekilde başka bir çalışmada, cep derinligi $4 \mathrm{~mm}$ 'yi geçen bölge sayısı ve gingival indeks ortalamaları ile erken dogum yapma riski arasında anlamlı bir ilişki olmadığı belirtilmiştir (Ataoğlu ve ark 2000). GDM ile periodontal hastalık arasında da ilişki olabileceği öne sürülmüştür (Xiong ve ark 2006, Chokwiriyachit ve ark 2013, Xiong ve ark 2009). Çalışmamızda, her iki gruba ait klinik periodontal verilerin benzer bulunması Dasanayeke ve arkadaşları (Dasanayake ve ark 2008) ile Xie ve arkadaşlarının (Xie ve ark 2013) bulguları ile uyumludur.

Gebelik ve periodontal hastalıklar arasındaki ilişkiler, çeşitli immün ve mikrobiyolojik mekanizmalarla açıklanmaya çalışılmıştır. İmmün sistem gebeliğe bağlı hormonal değişikliklerden etkilenmektedir. Gebelikte, nötrofil ve monosit fonksiyonlarında $(23,24)$, prostaglandin E2 salımında (Ogata 1995, Löe 1993) farklılıklar meydana geldiği vurgulanmaktadır. Periodontal hastalıkların gebelik komplikasyonlarını arttırıcı etkisi olduğu belirtilmiştir (Armitage 2013, Çetin ve ark 2012). Mikrobiyal dental plak mikroorganizmaları ve ürünlerinin plasental bölgeye ulaşması, ortaya çıkan medyatörlerin lokal ve sistemik etkileri ile periodontal hastalıkların gebelik komplikasyonlarının ortaya çıkma olasılığını arttırmaktadır (Armitage 2013, Çetin ve ark 2012). GDM dişında gebelik komplikasyonu bulunan gebeler bu çalışmaya dahil edilmemiştir. Bu nedenle, çalışmamızda gebelik komplikasyonları ve periodontal hastalık arasındaki ilişkiler değerlendirilmemiştir. Doğum haftası ve ağırlığı verileri incelendiğinde, erken doğum veya düşük doğum ağırlığı gibi komplikasyonlara rastlanmamıştır.

GDM'si olan gebelerde doğum sonrası glukoz ve insülin metabolizması normale dönmektedir (Otomo-Cargel ve ark 2012). Hiperglisemi döneminin sadece gebelik süresince oluştuğunu düşündüğümüzde bu süre periodontitis gibi destrüktif bir hastalığın ortaya çıkması için yeterli gibi görünmemektedir. Bu nedenle, bazı araştırıcılar enflamatuvar periodontal hastalığın GDM'nin sonucundan ziyade nedeni olabileceğini ileri sürmektedir (Xiong ve ark 2006, Chokwiriyachit ve ark 2013, Xiong ve ark 2009). Burada etkili olduğu öne sürülen mekanizma; periodontal hastalığa bağlı olarak artan lokal enflamatuvar medyatör seviyesi ile bakteri ve ürünlerinin sistemik enflamatuvar yanıtı hem başlattığı hem arttırdığı, sistemde artmış olan interlökin-1 (IL-1) ve tümör nekroz faktörü-alfa (TNFalfa) düzeylerinin ise pankreatik Beta-hücre yıkımına yol açarak insülin direnci gelişmesine neden olabileceği şeklindedir. Çalışmamızda değerlendirilen kadınların gebelik öncesine ait klinik periodontal verileri olmadığı için GDM ve eflamatuvar periodontal hastalıklar arasındaki ilişki değerlendirilememiştir. Xiong ve arkadaşlarının (Xiong ve ark 2006, Chokwiriyachit ve ark 2013, Xiong ve ark 2009) ileri sürdüğü periodontal hastalıkların GDM'nin nedeni olabileceği iddiasını değerlendirmek üzere klinik ve biyokimyasal verileri içeren çalışmalara ihtiyaç olduğunu düşünmekteyiz.

GDM'si olan kadınların bebeklerinde makrozomi, neonatal dönemde hipoglisemi, hipokalsemi gibi komplikasyonlar gelişebildiği bildirilmiştir (Ogata 1995, Löe 1993, Otomo-Cargel ve ark 2012). Çalışmalarda GDM'te makrozomi insidansı \%16-29 olarak bildirilirken, GDM'u olmayan kadınlarda bu oran \%10'dur. Çalışmamızda GDM'si olan kadınların makrozomi görülme oranı \%13,1'dir ve iki grup arasında anlamlı fark saptanmamıştır. Bu oranın Naylor ve arkadaşlarının (Naylor ve ark 1996) belirttiğinden düşük bulunmasının,yanı sıra Ogonowski ve arkadaşları (Ogonowski ve ark 2008) GDM'si olan ve olamayan kadınlarda anlamlı fark saptamamışlardır. Bu sonucun GDM'si olan bireylerin hamilelik süresince düzenli olarak bir endokrinoloji uzmanının kontrolü altında olmasından kaynaklandığını düşünmekteyiz. Yapılan çalışmalar GDM'nin kontrol altına alınması ile GDM'ye bağlı komplikasyonların azaltılabileceğini göstermiştir (Otomo-Cargel ve ark 2012). Aynı durum GDM ve periodontal hastalık arasındaki ilişkinin değerlendirilmesinde de geçerli olabilir. Bu hasta grubunun hekim kontrolünde olması, GDM'si olmayan grup ile benzer klinik periodontal veriler elde edilmesine yol açmış olabilir.

NT-ProBNP preklinik dönemde değerlendirilerek kardiyak hastalıkların erken tanısında önemli yarar sağlar (Lemos ve ark 2008). Kardiyak hastalıkların yanında diyabet gibi hastalıklarda da plazma düzeyleri değerlendirilmiştir (Hildebrandt ve Richards 2008, Feinkohl ve ark 2012). NT-ProBNP'nin GDM ile ilişkisini araştıran sadece bir çalışmada (Andreas ve ark 2011), farklı derecelerde GDM'si olan ve farklı tedavi uygulanan hastalar ile kontrol grubuna dahil olan bireylerde plazma NT-ProBNP düzeyleri değerlendirilmiştir. GDM'si olan gebelerde NTProBNP düzeyleri normal sınırlar içerisinde bulunmuştur. Bizim çalışmamızda da bu çalışmaya paralel olarak plazma NT-ProBNP değerleri GDM'si olan ve olmayan bireylerde benzer bulunmuştur. GDM'ye bağlı hiperglisemi sürecinin kısa olması gibi nedenlere bağlı olarak plazma NT-ProBNP düzeyleri 
çalışma gruplarında benzer bulunmuş olabilir.

Sonuç olarak, çalışmamızın bulguları GDM'nin enflamatuvar periodontal hastalık şiddetini arttırdığı görüşünü desteklememektedir. GDM'nin klinik periodontal veriler üzerine olan lokal etkisinin tükürük ve dişeti oluğu sıvısı içeriğindeki biyolojik belirteçler aracılığı ile değerlendirildiği çalışmalara intiyaç duyulduğunu düşünüyoruz.

\section{Teşekküir}

Ege Üniversitesi Tıp Fakültesi Biyoistatistik Anabilim Dalı'nda görevli Yrd.Doç.Dr. Timur Köse'ye istatistik analizleri gerçekleştirdiği için teşekkür ederiz.
Birinci büyük azı dişlerde çürük gelişme riskinde sabit ortodontik tedavinin etkisi

Amaç: Çok az araştırmada, gestasyonel diabetes mellitus (GDM) ile enflamatuvar periodontal hastalıkların olası ilişkisi incelenmiştir. $\mathrm{Bu}$ çalışmanın amacı, GDM'si olan ve olmayan gebelerde klinik periodontal durum ve plazma NT-ProBNP düzeylerinin karşılaştırmalı olarak incelenmesidir.

Gereç ve Yöntemler: Yükleme sonrası üç saat boyunca saatlik kan sekeri ölçümleri, açlık glukoz, açlık insülin ve HOMA-IR değerleri belirlenerek GDM tanısı konan 43 gebe ve GDM'si olmayan 41 gebe olmak üzere toplam 84 kadın çalışmaya dahil edildi. Plazma NT-ProBNP değerlendirmesi için venöz kan alınarak plazma örnekleri ayrıldı. Klinik periodontal durumun değerlendirilmesi için sondalama derinliği $(\mathrm{mm})$, klinik ataşman seviyesi $(\mathrm{mm})$, plak ve kanama indeksleri (\%) ağızdaki tüm dişlerin 4 bölgesinde ölçüldü. Gebelere ait polikistik over, düşük hikayesi, insülin direnci, sosyo-demografik veriler, doğum haftası ve bebeklerin doğum ağırlığı kaydedildi. İstatistiksel analizler için MannWhitney U Testi ve Pearson ki-kare testi kullanıldı.

Bulgular: GDM'si olan gebelerde yaş, açlık glukoz, açlık insülin, HOMA-IR, 1., 2. ve 3. saat glukoz değerlerinin GDM'si olmayan gebelere göre daha yüksek olduğu belirlendi $(p<0,05)$. Klinik periodontal veriler karşılaştıııldığında plak, kanama, ve sondalama derinliği ölçümleri her iki grupta benzer bulundu. Plazma NT-ProBNP seviyesi gruplar arasında anlamlı fark göstermedi.

Sonuç: Çalışmamızın bulguları, GDM ile enflamatuvar periodontal hastalık şiddeti arasında anlamlı bir ilişki göstermemektedir. Ancak, konunun daha büyük çalışma gruplarında ve farklı biyokimyasal veriler aracilığıyla irdelenmesinin yararlı olacağını düşünüyoruz.

\section{ANAHTAR KELIMELER}

Enflamasyon, gestasyonel diyabet, periodontal hastalık, plazma, 


\section{KAYNAKLAR}

Andreas M, Zeisler H, Handisurya A, Franz MB, Gottsauner-Wolf M, Wolzt M, Kautzky-Willer A, 2011. $N$ terminal-pro-brain natriuretic peptide is decreased in insulin dependent gestational diabetes mellitus: a prospective cohort trial. Cardiovasc Diabetol, 28, 1-4.

Armitage GC, 2013. Bi-directional relationship between pregnancy and periodontal disease. Periodontol 2000, 61, 160-76.

Ataoğlu T, Marakoğlu K, Gürsoy UK, Marakoğlu i, 2000. Oral fokal enfeksiyon odakları ile erken dogum ilişkisinin değerlendirilmesi. Cumhuriyet Üniversitesi Dishekimliği Fakültesi Dergisi, 2, 7173.

Buduneli N, Baylas $\mathrm{H}$, Buduneli $\mathrm{E}$, Türkoğlu $\mathrm{O}$, Köse T, Dahlen G, 2005. Periodontal infections and pre-term low birth weight: a case-control study. J Clin Periodontol, 32, 174-81.

Chokwiriyachit A, Dasanayake AP, Suwannarong W, Hormdee D, Sumanonta G, Prasertchareonsuk W, Wara-Aswapati N, Combellick J, Pitiphat W, 2013. Periodontitis and gestational diabetes mellitus in non-smoking females. J Periodontol, 84, 857-62.

Corbella S, Taschieri S, Francetti L, De Siena F, Del Fabbro M, 2012. Periodontal disease as a risk factor for adverse pregnancy outcomes: a systematic review and meta-analysis of casecontrol studies. Odontology, 100, 232-40.

Çetin I, Pileri P, Villa A, Calabrese S, Ottolenghi L, Abati S, 2012. Pathogenic mechanisms linking periodontal diseases with adverse pregnancy outcomes. Reprod Sci, 19, 633-41.

Dasanayake AP, Chhun N, Tanner AC, Craig RG, Lee MJ, Moore AF, Norman RG, 2008. Periodontal pathogens and gestational diabetes mellitus. J Dent Res, 87, 328-33.

Feinkohl I, Sattar N, Welsh P, Reynolds RM, Deary IJ, Strachan MW, Price JF, 2012. Association of $\mathrm{n}$-terminal pro-brain natriuretic peptide with cognitive function and depression in elderly people with type 2 diabetes. Plos One, 7 , e44569.

Hildebrandt P, Richards AM, 2008. Aminoterminal pro-b-type natriuretic peptide testing in patients with diabetes mellitus and with systemic hypertension. Am J Cardiol, 101 [suppl], 21A-24A

Karakurt F, Çarlıoğlu A, Kasapoğlu B, Gümüş ii, 2009. Gestasyonel diabetes mellitus tanı ve tedavisi. Yeni Tıp Dergisi, 26, 134-38.
Khader YS, Ta'ani Q, 2005. Periodontal diseases and the risk of preterm birth and low birth weight: a meta-analysis. J Periodontol, 76, 161-165.

Kumar A, Basra M, Begum N, Rani V, Rani V, Prasad S, Lamba AK, Verma M, Agarwal S, Sharma S, 2013. Association of maternal periodontal health with adverse pregnancy outcome. J Obstet Gynaecol Res, 39, 40-45.

Lemos J, Hildebrandt P, 2008. Amino-terminal pro-b-type natriuretic peptides: testing in general populations. Am J Cardiol, 101[suppl], 16A-20A.

Löe $H, 1993$. Periodontal disease. The sixth complication of diabetes mellitus. Diabetes Care, 16, 329-34.

Matthews DC, 2002. The relationship between diabetes and periodontal disease. J Can Dent Assoc, 68, 161-64.

Miyagi $\mathrm{M}$, Aoyama $\mathrm{H}$, Morishita $\mathrm{M}$, Iwamoto $\mathrm{Y}$, 1992. Effects of sex hormones on chemotaxis of human peripheral polymorphonuclear leukocytes and monocytes. J Periodontol, 63, 28-32.

Miyagi M, Morishita M, Iwamoto Y, 1993. Effects of sex hormones on production of prostaglandin E2 by human peripheral monocytes. J Periodontol, 64, 1075-78.

Naylor CD, Sermer M, Chen E, Sykora K, 1996. Cesarean delivery in relation to birth weight and gestational glucose tolerance. Pathophysiology or practice style? JAMA, 275, 1165-70.

Ogata ES, 1995. Perinatal morbidity in offspring of diabetic mothers. Diabetes Rev, 3, 652-57.

Ogonowski J, Miazgowski T, Czeszynska MB, Jaskot B, Kuczynska M, Celewicz Z, 2008. Factors influcing risk of macrosomia in women with gestational diabetes mellitus undergoing intensive diabetic care. Diabetes Res Clin Pract, 80, 405-10.

Otomo-Corgel J, Pucher JJ, Rethman MP, Reynolds MA, 2012. State of the science: chronic periodontitis and systemic health. J Evid Based Dent Pract, 12(Suppl), 20-28.

Ovadia R, Zirdok R, Diaz-Romero RM, 2007. Relationship between pregnancy and periodontal disease. Facta Universitatis Series: Medicine and Biology, 14, 10-14. 
Raber-Durlacher JE, Van Steenbergen TJM, Van der Velden U, de Graaff J, Abraham-Inpijn L, 1994. Experimental gingivitis during pregnancy and postpartum: clinical, endocrinological, and microbiological aspects. J Clin Periodontol, 21, 549558.

Turok DK, Ratcliffe SD, Baxley AG, 2003. Management of gestational diabetes mellitus. Am Fam Physician, 68, 1769-72.

Xie Y, Xiong X, Elkind-Hirsch KE, Pridjian G, Maney $P$, Delarosa RL, Buekens P, 2013. Change of periodontal disease status during and after pregnancy. J Periodontol, 84, 725-731.

Xiong X, Buekens P, Vastardis S, Pridjian G, 2006. Periodontal disease and gestational diabetes mellitus. Am J Obstet Gynecol, 195, 1086-89.

Xiong X, Elkind-Hirsch KE, Vastardis S, Delarosa RL, Pridjian G, Buekens $P, 2009$. Periodontal disease is associated with gestational diabetes mellitus: A case-control study. J Periodontol, 80, 1742-49.

\section{Yazışma Adresi:}

Doç.Dr.Özgün ÖZÇAKA

Ege Üniversitesi Diş Hekimliği Fakültesi

Periodontoloji AD Bornova/iZMiR

Tel : +90 2323881105

Fax: +90 2323880325

E-mail: ozgunozcaka@yahoo.com. 